\section{A CASE OF DESQUAMATIVE ERYTHEMA.}

By ATHELSTANE NOBBS, M.D. EdIN.

THE following case, which I assume was purely of the type known as erythema scarlatiniforme desquamativum, presents one or two points of interest that may be helpful not only in determining its position as a simple erythema - which has occasionally been questioned-and not a dermatitis, but also as possibly indicating, if not actually the elucidation of its etiology, at least a suggestion as to its causation.

Briefly, it occurred in the case of an old patient of mine, a man, aged 62 years, a mechanical engineer by profession. I am perfectly satisfied that syphilis could safely be eliminated in this connexion and the usual queries as to the possibility of contact with any case of scarlet fever, the incidence of toxic elements, such as fish, tinned foods, sausage, or the recent use of drugs, such as antipyrin, atropine, and so forth, elicited negative replies. The family history was good, as was also his own. Practically no cause was ascribable. During the whole illness, which lasted for about six weeks from the day when be first complained of malaise until the soles of his feet were shed practically en masse, there was absolutely no rise of temperature, the mercury for the most part hovering in the neighbourhood of $97^{\circ} \mathrm{F}$. There was no albuminuria and no glandular enlargement, save notably a slight fulness of the thyroid, coupled with some tenderness on pressure of that organ not to be confounded with, nor mistaken for, sub. maxillary lymphangitis. The course of the disease was typical, the "boiled-lobster" rash speedily following the prodromal symptoms, commencing on the abdomen and then rapidly invading the rest of the trunk and eventually the extremities. Desquamation, which ensued about the eighth day, was profuse, varying in character from the consistency of powdery squamules as it fell from the trunk, neck, and limbs to scales of the saurian type such as one sees in ichthyosis. This latter condition was most marked on the forehead and the flexor surfaces of the forearm, and again on the extensor surfaces of the legs and ankles. The treatment was rest, with milk diet, then vegetarian regimen, and eventually a return to ordinary fare, and by way of a medicinal standby sodium phosphate in laxative doses. There never was any itchiness, though the patient complained of feeling as if his skin would burst, which, indeed, the dying epidermis ultimately did, and for the first week there was "tenderness" in swallowing, tobacco irritated the tongue, and there was some photophobia. As the mucosæ were involved in the general congestion of the epiblastic tissues this was only to be expected, but it is noteworthy that despite the universal vascular disturbance of the surface of practically the whole body there was no sign of cerebral irritation nor yet of the faintest degree of hyperæmia of the endothelial structures.

In such a short sketch as this it is idle to adduce a variety of arguments but the following points certainly occurred to me. Firstly, if this case was simply one of erythema, as I fully believe it was, either it should be classified as a benign exanthem, by which I mean a noncontagious one, or else as a symptom of some diseased condition, of which the primal cause is as yet undetermined. In any case $I$ deprecate the use of a misnomer with an "itis" suffix, such as dermatitis exfoliativa, which lacks two at least of the cardinal points relating to inflammationnamely, pain and heat-though connoting them. Secondly, there seemed to my mind to be some connexion between the disturbed condition of the thyroid gland and that of the cutis most noticeable, as it was, during the desquamative process. We all know that dried horny scales of the cutis are more or less perpetually being shed whether one is ill or well; but although $I$ know it is illogical to attempt even to argue from a special point to a general rule, I cannot divest myself of the idea that the activity of the gland alluded to was sympathetic and that it may have, and did have, an influence as much in the nature of cause as of effect and was probably more incidental than accidenta]. The disease, lastly, is said to be rare even in adults, but $I$ cannot help wondering how many such find their way to the wards of the fever hospitals.

London.

\section{A}

\section{HOSPITAL PRACTICE, BRITISH AND FOREIGN.}

Nulla autem est alia pro certo noscendi via, nisi quamplurimas ot morborum et dissectionum historias, tum aliorum tum proprias Morb., lib. iv., Proœmium.

\section{UNIVERSTTY COLLEGE HOSPITAL.}

A CASE OF FeMORAL ANEURYSM; EXCISION ; CURE. (Under the care of Mr. Bilton PollaRd.)

For the notes of the case we are indebted to Mr. P. Maynard Heath, late surgical registrar.

A man, aged 37 years, complained of weakness and swelling of the left leg and a throbbing tumour in the left groin. The swelling in the groin first appeared in 1901. It gradually increased in size and became very painful, while the leg became swollen. About two months after the first appearance of the swelling he was admitted to the Civil Hospital, Hong-Kong, where the external iliac artery was ligatured. The pulsation in the tumour ceased for about a fortnight and then reappeared. The ligature was said to have slipped and an anæsthetic was again administered and the artery was said to have been religatured. In 1904 the aneurysm had become as troublesome as it had been originally. He had had syphilis ten years previously and had been treated for two months.

On admission to University College Hospital on Sept.22nd, 1906 , he was found to be a heavily built, well-nourished man. In the left groin was a swelling which filled Scarpa's triangle and on the surface of this just below Poupart's ligament was a prominence the size of a walnut. The latter was illdefined above but sharply outlined elsewhere. The skin over it was normal. There was slight but definite expansile pulsation in the superficial prominence but no pulsation could be detected in the main mass of the swelling. The pulse in the artery below was weaker than on the right side and was slightly delayed. Pressure on the external iliac artery led to diminution in the pulsation of the aneurysm but it was impossible completely to control it. Immediately above Poupart's ligament was the oblique scar of the previous operation. The oedema of the leg had subsided as the result of rest in bed, but the whole of the left thigh was much bigger than its fellow. No other aneurysms could be found. The heart's impulse was very weak and a double murmur was present at the apex. The second sound was considerably accentuated. A moderate degree of arterio-sclerosis was present. On Oct. 4th continuous digital compression of the external iliac artery was carried out for eight and a half hours. No effect on the aneurysm was perceptible. On the 19th a vertical incision was made downwards from the old scar for about nine inches. The surface of the aneurysm was exposed and cleared and it was then found that the above noted prominence was a seconclary dilatation of the large mass which lay more deeply. The mass was first cleared on the outer side, the anterior crural nerve being exposed and held aside. The parts surrounding the aneurysm were greatly matted together and after a prolonged dissection the deep circumflex iliac artery was found and ligatured and the external iliac artery was recognised. In the process of clearing it the deep epigastric artery was wounded. It was ligatured, the external iliac artery being secured above its point of origin. The superficial femoral artery was then exposed and ligatured below the aneurysm. Even after this stage the aneurysm still pulsated. It was then found that the femoral vein was closely incorporated with the sac of the aneurysm on the inner side. Part of the sac was therefore cut away and left attached to the vein, and the aneurysm was rapidly turned downwards and removed. Several large vessels were involved at the back of the sac but they were readily controlled by forceps. It was then found that a longitudinal wound about three-quarters of an inch in length had been made in the femoral vein. The rent was closed by a continuous suture of fine silk. Immediately below this wound a large vein, probably the profunda, entered the main vein. All divided vessels were then ligatured and the skin wound was partly closed, a drainage-tube being introduced. 